\title{
Patterns of Residential Mobility Amongst Children in Greater Johannesburg-Soweto, South Africa: Observations from the Birth to Twenty Cohort
}

\author{
Carren Ginsburg • Shane A. Norris • \\ Linda M. Richter • David B. Coplan
}

Published online: 4 September 2009

(C) The Author(s) 2009. This article is published with open access at Springerlink.com

\begin{abstract}
Frequent residential movement challenges children to adapt to change, amongst others, houses and neighbourhoods, friends and schools, and this may have either or both negative and positive influences on their health and well-being. However, there is currently little knowledge of the patterns of child residential mobility within South Africa's urban environment. This paper uses address data of children in the Birth to Twenty cohort to analyse the frequencies and patterns of residential mobility observed over the first 14 years of these children's lives. Of the 3,273 children enrolled into the cohort in 1990, two thirds of the children $(64 \%)$ have moved home at least once. Nonetheless, a third of the children never moved,
\end{abstract}

C. Ginsburg $(\bowtie)$

Birth to Twenty Research Programme, Department of Paediatrics and Child Health, University of the Witwatersrand, 7 York Road, Parktown, Johannesburg 2193, South Africa e-mail: carren.ginsburg@wits.ac.za

\section{S. A. Norris}

MRC Mineral Metabolism Research Unit and Birth to Twenty Research Programme,

Department of Paediatrics, University of the Witwatersrand, Johannesburg, South Africa

L. M. Richter

Child, Youth and Family Development, Human Sciences Research Council, Durban, South Africa

L. M. Richter

School of Psychology, University of KwaZulu-Natal, Durban, South Africa

L. M. Richter

Birth to Twenty Research Programme, Department of Paediatrics, University of the Witwatersrand, Johannesburg, South Africa

D. B. Coplan

Department of Social Anthropology, University of the Witwatersrand, Johannesburg, South Africa 
indicating some stability among the urban child population. Residential moves by children were found to be associated with both the lowest resourced and the highest resourced households.

Keywords Residential mobility · Migration · Urban children · South Africa

\section{Introduction}

Movement patterns in South Africa have assumed a unique form as a result of the country's political and social history (Wentzel and Tlabela 2006). Forced and controlled migration took root in Southern Africa with the British colonial system encouraging circular migration and discouraging permanent urban settlement amongst native populations recruited from rural surrounds as members of an urban work force (Crush 2000; Hargrove 2007). With the onset of the Apartheid system in South Africa, a series of legislative initiatives were introduced, which sought to further control the movement and settlement of specifically Black South Africans. The system of movement (influx) control and the introduction of the Group Areas Act, were amongst the segregationalist policies concerned with restricting Black urbanisation and regulating the accommodation of Black workers in urban areas, while simultaneously ensuring that labour demands in urban areas could be met (Giliomee and Schlemmer 1985; Posel 1991). A prominent characteristic of this simultaneous labour market and residential control was oscillatory migration, primarily of men, between urban locations of employment and rural homesteads where women and children remained (Wilson 1972). As a result, residential arrangements fluctuated with fluid household structures of varying sizes and compositions (Murray 1981). The end of Apartheid and the years following South Africa's transition to democracy have seen a marked relative rise in rates of urbanisation amongst Black people (Kok and Collinson 2006; Statistics South Africa 2007).

Despite the absence of legal barriers to movement, there is evidence that the oscillatory labour migration trends have not significantly altered, nor have they been replaced by increases in permanent urban settlement that might have been anticipated (Posel 2006). Furthermore, rises in female labour migration have been observed as increasing numbers of women enter the labour market in an environment of changing work conditions and social roles (Posel and Casale 2003; Collinson et al. 2006a).

In the context of a highly mobile adult population, corresponding patterns of movement amongst children have been investigated only minimally. Current South African research has shown that patterns of movement involving children can take place within urban or rural environments, or between rural and urban areas, and that they can be either permanent or temporary (Collinson et al. 2006a). Children have been reported to move either together with one or more primary caregivers or independent of them (Van der Waal 1996). Movement may be prompted primarily by the connected adult/s (who may move to access an employment opportunity, or in response to relationship formation/dissolution). Movement may also be motivated by children's specific needs or circumstances such as movement to gain access to education, or movement in response to the death of a caregiver (Van der Waal 1996; 
Ford and Hosegood 2005; Collinson et al. 2006a). Motives for moves are, however, unlikely to be clear cut, and may result from decision-making with consideration of both adult and child factors. In addition, child care arrangements may be fluid with children shifting between homes in order to maximise access to care and resources, or to provide support to extended kin through the mechanism of child fosterage (Jones 1993; Van der Waal 1996). Nevertheless, there is a dearth of research on children's movement patterns in South Africa and in other low- and middle-income countries.

The lack of information about child migration stems from the fact that most data concerning population movements in South Africa have been collected as part of cross-sectional national population censuses, which are primarily concerned with investigating economically active adults and inter-provincial movements (Hosegood and Ford 2003). These surveys pose problems in the investigation of child movements for the following reasons: they are centred on the household rather than the individual as the unit of analysis, there are complexities associated with measuring and defining mobility of children in terms of their connection to related adults or households, and there are difficulties associated with gaining access to mobile children for the purpose of data collection. Studies using demographic surveillance systems such as those based at Agincourt and Mtubatuba have investigated the movements of children as members of households in rural South Africa. However, there is no published research directly exploring residential mobility amongst children born and residing in urban areas of South Africa.

The urban environment is often thought to promise higher standards of living though easier access to health care, social services, employment and educational facilities. However, urban systems frequently reinforce patterns of inequality and poverty, thus increasing the vulnerability of the poor (South African Cities Network 2006). Recent migrants to urban areas have been found to be particularly disadvantaged by negative aspects of urban living such as over-crowding, inadequate housing and amenities, material deprivation and crime (Brockerhoff 1995; Richter et al. 2006). In such circumstances, children are particularly vulnerable to a range of negative health and social consequences (Barbarin and Richter 2001). Research conducted in developing countries has linked high levels of mobility amongst children to a range of negative health and social consequences such as increased child mortality, susceptibility to disease, exposure to violence and increased psychological distress (Magwaza 1994; Brockerhoff 1995; Barbarin and Richter 2001; Garenne 2003). However, mobility may also be associated with improved standards of living and health (Collinson et al. 2006b). The relationship between urbanisation and mobility and their associations with child health and well-being is complex and has been shown to be influenced by the form the migration takes, as well as a range of confounders including residential arrangements, family and household structures and socioeconomic status (Collinson et al. 2006b; Tucker et al. 1998; Garenne 2003). There has been limited research in the developing country context to understand the associations between mobility, household structures and child well-being.

South Africa's largest urban population is based within the Greater Johannesburg/ Soweto area (in the Gauteng Province), which is also the largest receiver of net in- 
migrants from other provinces in the country - across all population groups (Kok et al. 2003; Statistics South Africa 2006). The attractiveness of Gauteng as a migration destination stems largely from the fact that the province is the economic hub of South Africa with the highest reported employment growth rates (South African Cities Network 2006). Within the Gauteng Province, relatively high levels of adult residential movement and circular migration have been observed, often in response to opportunities for employment, education, transportation and housing (Rule 2000; Richter et al. 2004). The Greater Johannesburg/Soweto area provides an appropriate context in which to explore patterns of residential mobility amongst a group of urban South African children who form part of the Birth to Twenty cohort.

This paper presents results from a 14-year longitudinal study of child residential movement in the Greater Johannesburg area, using data collected through the Birth to Twenty Research Programme (BT20). BT20 is a longitudinal birth cohort study, and, as such, is in a unique position to address research questions concerning changing social dynamics over time. The paper describes the movement patterns and frequencies of child residential mobility as well as elicited reasons prompting residential change. Key demographic factors associated with differing levels of residential movement are also considered.

\section{Methods}

\section{Study Sample and Protocol}

The BT20 cohort was defined to include all children born within a 7-week period between April and June 1990 at public delivery centres in the Greater Johannesburg Metropolitan Area, including Soweto and Diepmeadow. The cohort was further refined to include only those women and children who were identified as having a residential address in Johannesburg-Soweto both at the time of delivery, and in the 6 months following the birth of the child, to exclude non-residential women who came into Johannesburg/Soweto only to deliver their baby. Upon inception of the study, the longitudinal sample comprised a residential cohort of 3,273 children. The research aims and goals of the BT20 project, and characteristics of the sample, are described elsewhere (see Richter et al. 2004, 2007).

At recruitment, the BT20 cohort was demographically representative of the area. The largest proportion of children in the cohort was Black (78.5\%), born at a public hospital $(86.5 \%)$ and resident in the Soweto/Diepmeadow area at birth $(74.2 \%)$. White, Coloured and Asian children made up 6.3\%, 11.7\% and 3.5\% of the cohort, respectively. Biological mothers were primarily aged between 19 and 34 years $(79.3 \%)$ at the time of the birth of their BT20 child, at which time $56.1 \%$ were single and $50.8 \%$ had commenced primary but not completed secondary school.

The study of residential movement described in this paper comprised four phases. In the first phase, historical address data were collated and summarised to generate a profile of address information for each participant. In the second phase the historical address data were used as a base for designing and developing a survey instrument to probe children's residential movements. In the third phase, the questionnaire was administered to as many of the contactable cohort members as possible, yielding a 
sample of 2,158 complete questionnaires $(66 \%$ of the original cohort of 3,273$)$. The final phase of the study involved preparing and analysing all available address data relating to both the movement survey respondents and the identified non-contactable cohort members, or attrition cases (amounting to 1,115 members of the original residential cohort). This was an attempt to deal with the methodological limitation of excluding untraceable participants when analysing mobility.

\section{Construction of Historical Address Profiles for Years 1989-2004}

Over the 15 years of the BT20 study, address data were collected and maintained in a database for the purpose of corresponding with and locating participants and managing and monitoring study attrition (Anderson and Richter 1994; Norris et al. 2007). At the onset of the BT20 study, data collection was conducted in health centres and by field staff who visited participants' homes and documented addresses. In the later years of the study, addresses were updated when participants visited one of the BT20 data collection sites at the Johannesburg General or Chris Hani Baragwanath Hospitals, or when follow-up and data collection was conducted during a home visit. For the current analysis, address data were available at each of the ten data collection time points that spanned the years 1989 to 2004 , commencing when the BT20 child was born, and continuing when the child was aged 1, 2, 3/4, 5/6, 7/8, 9/10, 11/12, 13 and 14 years. These historical address records were consolidated to obtain a longitudinal database describing the movement history for each participant.

\section{Construction of the Survey Instrument}

The longitudinal database had several limitations for utilising the data to specifically describe children's movements. For example, contact details on record often reflected the place of residence of the BT20 child's biological mother or primary caregiver, which was found not always to correspond to the BT20 child's place of residence. Therefore, a Residential Move Questionnaire was developed with the aim of addressing these limitations and obtaining further information about children's movements. The questionnaire was designed to incorporate all longitudinal data which could be verified by respondents as reflecting the place of residence of the BT20 child. The questionnaire also allowed for the completion of any missing address components or undocumented moves involving the BT20 child. Finally, the questionnaire included the central reasons prompting movement which were recorded verbatim through an open-ended question to which respondents were free to explain in their own words why the move had taken place. The questionnaire was structured around the set of ten discrete time points that corresponded to BT20's historical data collection waves between 1989 and 2004 .

\section{Implementation of the Study Protocol}

Data collection on the Residential Move Questionnaire took place at participant's homes and at the BT20 offices during BT20's years 15 and 16 data collection waves. Questionnaires were administered in the form of a structured interview. Preference was 
given to conducting the interviews with children's primary caregivers as they were deemed to have the most knowledge of a child's residential movements over time. Questionnaires were administered by members of a team of trained field staff and an ongoing system of training and quality checking of questionnaires was implemented. The majority of questionnaire respondents were biological mothers or primary caregivers $(82 \%)$, with the balance of questionnaires completed by a family or household member who verified that they had knowledge of the BT20 child's residential movements.

\section{Data Analysis}

Due to the strong association between sample attrition and child and family movement, the known residential movements relating to the 1,115 cases of documented cumulative attrition were compiled and included in the current study. Survey data was therefore merged with the residential movement data available from the attrition sample in order to describe the overall movement patterns of children in the cohort. The analytical dataset was then reduced to the sample of 2,158 participants who had completed the Residential Move Questionnaire, where more detail about the classification of moves, reasons for movement and characteristics associated with differing movement profiles could be analysed. A socioeconomic index was derived for each participant on the basis of access to a set of ten services and household assets (house type, house ownership, indoor water, flush toilet, electricity, television, car, fridge, washing machine and telephone), which were summed and participants grouped into quartiles. Data analysis was conducted using SPSS; descriptive statistics were utilised to identify patterns and frequencies of mobility within the cohort, and chi-square tests were employed to establish significance of associations.

\section{Results}

Overall Movement Within the Cohort

Based on the pooled sample of 3,273 participants, an analysis of the frequency of children's summed residential movements over the period commencing at birth until the age of 14 years revealed a total of $1,169(35.7 \%)$ children who had never experienced a residential move, with two thirds of children (64.3\%) having moved home one or more times. Of the 2,104 children who had experienced a residential move, $60.1 \%$ had changed residence only once, $28.9 \%$ had moved twice and $10.9 \%$ had moved three or more times. The chart presented in Fig. 1 contrasts the frequency of moves for the children who comprised the cumulative attrition group-that is, who were lost to follow-up - and the children who remained in the study and completed the Residential Move Questionnaire. The difference between the movement profiles of the two groups was significant $\left(\chi_{(4)}^{2}=230.149, p<0.001\right.$, $n=3,273$ ) with children who were lost to follow-up having experienced a higher recorded frequency of residential movement $(81.3 \%$ having moved one or more times, and an average of $13.3 \%$ of the group moving home at any one time point) as compared with the children who had remained in contact with the BT20 study 


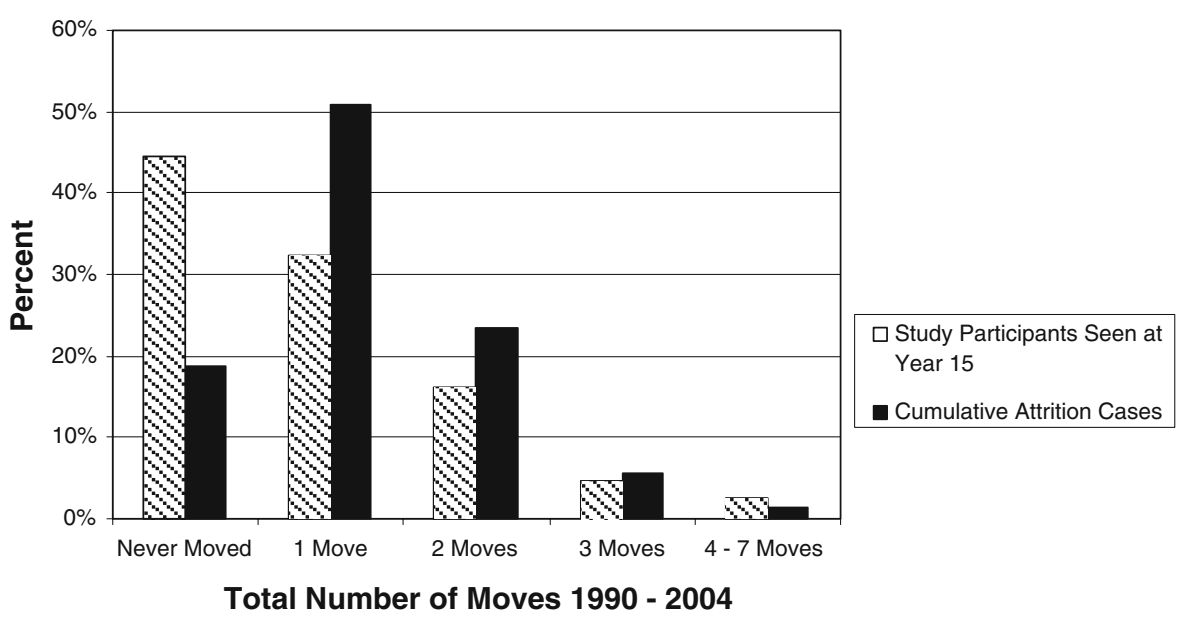

Fig. 1 Longitudinal summary of the frequency of residential movement from 1990-2004

(55.5\% having moved one or more times, with an average of $9.9 \%$ of the group changing residence at any one time point).

Comparative analyses performed between the cumulative attrition sample and the sample of participants who completed the Residential Move Questionnaire revealed that, in contrast with the study participants seen at years 15 and 16 , the cumulative attrition group comprised higher levels of White participants $(12.6 \%$ as compared with $3.1 \%$ for year $\left.15 ; \chi_{(3)}^{2}=121.597, p<0.001, n=3,273\right)$, children born in private hospitals $\left(16.2 \%\right.$ as compared with $\left.12.1 \% ; \chi_{(1)}^{2}=11.010, p<0.01, n=3,272\right)$ and residents in the inner city or suburbs at birth $(5.1 \%$ as compared with $0.6 \%$, and $20.3 \%$ as compared with $5.4 \%$ respectively; $\chi_{(3)}^{2}=258.953, p<0.001, n=3,273$ ). Biological mothers whose children were lost to follow-up were more likely to have been married (52.1\% as compared with $\left.39.1 \% ; \chi_{(1)}^{2}=50.573, p<0.001, n=3,251\right)$, with either no formal education or a post-school education $(3.1 \%$ as compared with $0.9 \%$, and $14.0 \%$ as compared with $9.8 \%$, respectively; $\chi_{(3)}^{2}=36.991, p<0.001$, $n=2,932$ ). In addition, the cumulative attrition group comprised relatively higher proportions from the lowest resourced households (with access to three or fewer assets and services) and the highest resourced households (with access to between eight and ten assets and services; $38.0 \%$ as compared with $24.9 \%$, and $24.1 \%$ as compared with $17.9 \%$, respectively; $\left.\chi_{(3)}^{2}=65.709, p<0.001, n=2,054\right)$.

The movement profile and sample characteristics of the two groups over time are displayed in Table 1. The number of attrition cases increased at each data collection wave, with 66 children lost to follow-up at the start of year 1 (2.0\% of the cohort) and a total of 1,115 children lost to follow-up by the start of year 15 data collection $(34.1 \%$ of the cohort). Movement levels in the cohort were highest when children were aged between 3 and 4 years (19.3\% of children changed residence at this time), followed by relatively high levels of movement when children were aged between 11 and 12 years (14.9\%). Furthermore, the cumulative attrition group accounted for the majority of total residential movement between the ages 2 to 4 years $(56.6 \%$ and $64.9 \%$ of total moves over the two data collection waves were attributed to this group). 
Table 1 Sample characteristics and movement profile by data collection wave

\begin{tabular}{|c|c|c|c|c|c|c|c|c|c|}
\hline & \multicolumn{9}{|c|}{ Data collection wave } \\
\hline & $\begin{array}{l}\text { Year } \\
1\end{array}$ & $\begin{array}{l}\text { Year } \\
2\end{array}$ & $\begin{array}{l}\text { Year } \\
3 / 4\end{array}$ & $\begin{array}{l}\text { Year } \\
5 / 6\end{array}$ & $\begin{array}{l}\text { Year } \\
7 / 8\end{array}$ & $\begin{array}{l}\text { Year } \\
9 / 10\end{array}$ & $\begin{array}{l}\text { Year } \\
11 / 12\end{array}$ & $\begin{array}{l}\text { Year } \\
13\end{array}$ & $\begin{array}{l}\text { Year } \\
14\end{array}$ \\
\hline Total cohort & 3,273 & 3,273 & 3,273 & 3,273 & 3,273 & 3,273 & 3,273 & 3,273 & 3,273 \\
\hline $\begin{array}{l}\text { Sample of participants } \\
\text { who completed the } \\
\text { Residential Move } \\
\text { Questionnaire }\end{array}$ & 2,158 & 2,158 & 2,158 & 2,158 & 2,158 & 2,158 & 2,158 & 2,158 & 2,158 \\
\hline $\begin{array}{l}\text { Sample of cumulative } \\
\text { attrition cases lost to } \\
\text { follow-up ( } \% \\
\text { of cohort) }\end{array}$ & $\begin{array}{l}66 \\
(2.0)\end{array}$ & $\begin{array}{l}144 \\
(4.4)\end{array}$ & $\begin{array}{l}293 \\
(8.9)\end{array}$ & $\begin{array}{l}499 \\
(15.3)\end{array}$ & $\begin{array}{l}559 \\
(17.1)\end{array}$ & $\begin{array}{l}670 \\
(20.5)\end{array}$ & $\begin{array}{l}732 \\
(22.4)\end{array}$ & $\begin{array}{l}1,013 \\
(30.9)\end{array}$ & $\begin{array}{r}1,037 \\
(31.7)\end{array}$ \\
\hline $\begin{array}{l}\text { Total movement of full } \\
\text { cohort ( } \% \text { of cohort) }\end{array}$ & $\begin{array}{l}329 \\
(10.1)\end{array}$ & $\begin{array}{l}410 \\
(12.5)\end{array}$ & $\begin{array}{l}630 \\
(19.3)\end{array}$ & $\begin{array}{l}341 \\
(10.4)\end{array}$ & $\begin{array}{l}397 \\
(12.1)\end{array}$ & $\begin{array}{l}289 \\
(8.8)\end{array}$ & $\begin{array}{l}487 \\
(14.9)\end{array}$ & $\begin{array}{l}185 \\
(5.7)\end{array}$ & $\begin{array}{l}199 \\
(6.1)\end{array}$ \\
\hline $\begin{array}{l}\text { Movement linked to } \\
\text { cumulative attrition } \\
\text { sample (\% of total } \\
\text { movement) }\end{array}$ & $\begin{array}{l}125 \\
(38.0)\end{array}$ & $\begin{array}{l}232 \\
(56.6)\end{array}$ & $\begin{array}{l}409 \\
(64.9)\end{array}$ & $\begin{array}{l}108 \\
(31.7)\end{array}$ & $\begin{array}{l}136 \\
(34.3)\end{array}$ & $\begin{array}{l}44 \\
(15.2)\end{array}$ & $\begin{array}{l}212 \\
(43.5)\end{array}$ & $\begin{array}{l}15 \\
(8.1)\end{array}$ & $\begin{array}{l}56 \\
(28.1)\end{array}$ \\
\hline
\end{tabular}

\section{Number of Residential Moves at Each Time Point by Move Category}

The distribution of residential moves by category of move is presented in Fig. 2. The chart depicts, at each of the ten data collection time points, the proportion of total moves that occurred either within the Greater Johannesburg area or outside of it. Moves were accounted for in full. Therefore where a move occurred but knowledge of the destination of the move was uncertain, it was included into the analysis (as a

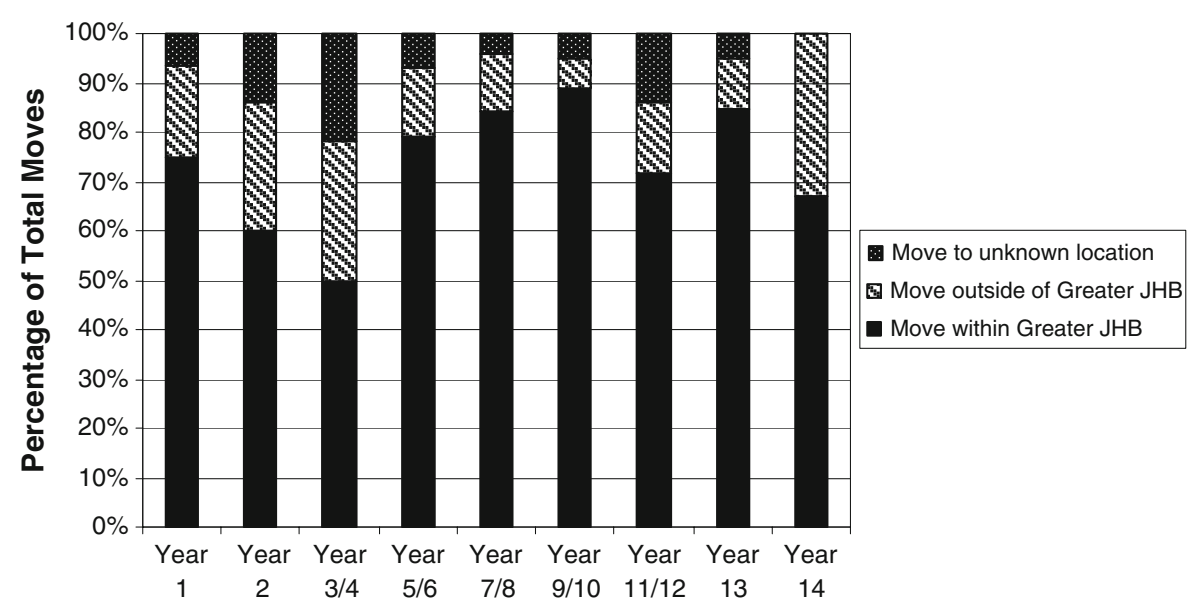

Data Collection Time Point

Fig. 2 Cross-sectional number of residential moves at each time point by move category 
move to an unknown location). At each of the ten time points, the largest proportion of moves involved intra-urban mobility-movement that took place within the greater Johannesburg area. Moves outside of Greater Johannesburg occurred more frequently in early childhood (below the age of 5 years), or when children were in their 14 th year $(28.3 \%$ and $33.2 \%$, respectively). Amongst the cumulative attrition group, $36.6 \%$ of total moves took place within Greater Johannesburg, 37.4\% of moves were to destinations outside of Greater Johannesburg and $26.0 \%$ of moves were to an unknown destination. In contrast, $94.2 \%$ of movements within the group of current participants took place within the Greater Johannesburg area, with only $5.9 \%$ of movement within this group involving relocation outside of the study area.

\section{Distribution of Moves Within Gauteng}

The Residential Move Questionnaire allowed for a more detailed classification of the spatial dimension of children's residential movements within the Gauteng Province. Moves were grouped according to whether they involved a change in dwelling within the same street, a change in street within the same suburb, a change of suburb within the same town or city, or a change in town or city within the Province (codes were assigned by consulting maps and sources detailing towns, cities and regions of each of the six metropolitan/district municipalities within Gauteng). As illustrated in Fig. 3, the largest proportion of cumulative moves between 1990 and 2004 within the Gauteng Province occurred between suburbs within the same town or city $(47.8 \%)$, with the lowest number of moves occurring over shortest distances such as moves within the same street $(1.1 \%)$.

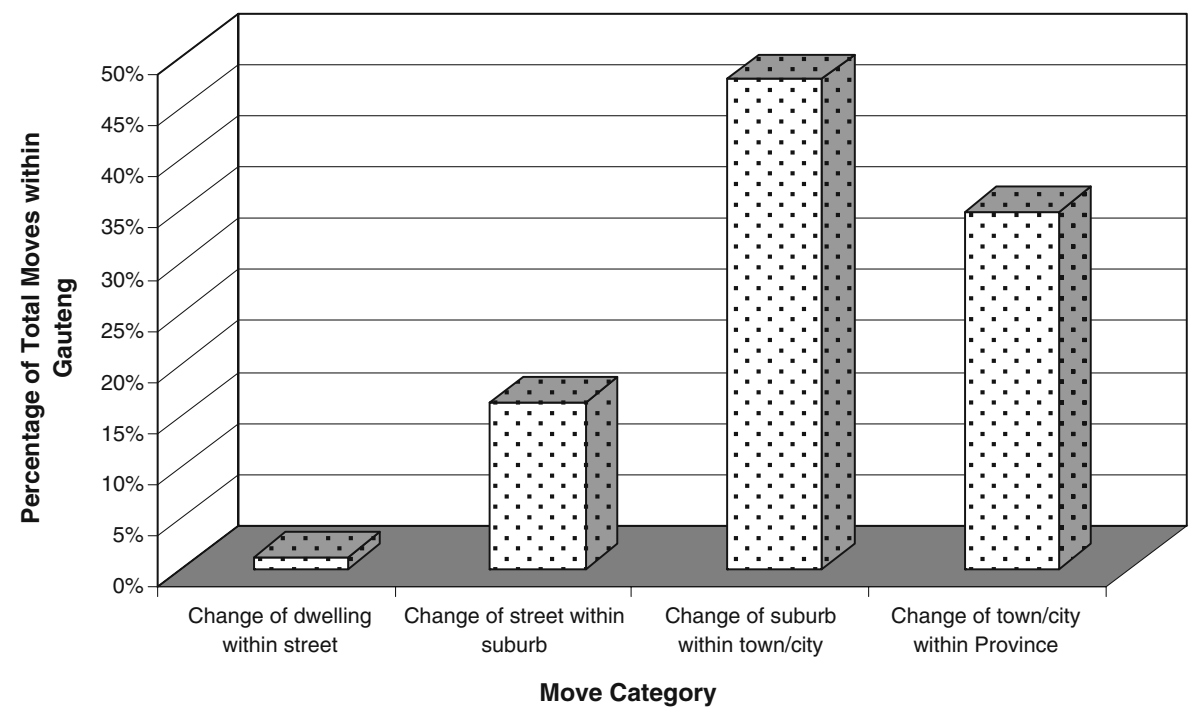

Fig. 3 Cumulative residential move categories for participants seen at year 15 


\section{Differences in Characteristics of Movers and Non-movers}

In order to generate a profile of children who had experienced a move as compared with children who had not moved home by age 14, a set of demographic variables were tested for significance across the two groups, and the results are displayed in Table 2. Significant differences were found across all the demographic variables

Table 2 Characteristics of movers and non-movers

\begin{tabular}{|c|c|c|c|}
\hline \multicolumn{2}{|c|}{ Characteristics by movement profile } & \multirow{2}{*}{$\begin{array}{l}\begin{array}{l}\text { Never moved total }(\%) \\
n=960\end{array} \\
484(50.4)\end{array}$} & \multirow{2}{*}{$\begin{array}{l}\begin{array}{l}\text { Moved total (\%) } \\
n=1198\end{array} \\
569(47.5)\end{array}$} \\
\hline Child gender & Male & & \\
\hline & Female & $476(49.6)$ & $629(52.5)$ \\
\hline \multicolumn{4}{|l|}{$\chi_{(1)}^{2}=1.820, \mathrm{NS}, n=2,158$} \\
\hline \multirow[t]{4}{*}{ Population group } & Black & $776(80.8)$ & $970(81.0)$ \\
\hline & White & $22(2.3)$ & $44(3.7)$ \\
\hline & Coloured & $139(14.5)$ & $139(11.6)$ \\
\hline & Asian & $23(2.4)$ & $45(3.8)$ \\
\hline \multicolumn{4}{|c|}{$\chi_{(3)}^{2}=9.878, p<0.05, n=2,158$} \\
\hline \multirow[t]{2}{*}{ Hospital of birth } & Public hospital & $862(89.8)$ & $1,035(86.5)$ \\
\hline & Private hospital & $98(10.2)$ & $162(13.5)$ \\
\hline \multicolumn{4}{|c|}{$\chi_{(1)}^{2}=5.558, p<0.05, n=2,157$} \\
\hline \multirow[t]{4}{*}{ Residential area at birth } & Soweto/Diepmeadow & $774(80.6)$ & $944(78.8)$ \\
\hline & Former Indian/coloured areas & $147(15.3)$ & $164(13.7)$ \\
\hline & Inner city & $0(0.0)$ & $12(1.0)$ \\
\hline & Suburban JHB & $39(4.1)$ & $78(6.5)$ \\
\hline \multicolumn{4}{|c|}{$\chi_{(3)}^{2}=16.706, p<0.01, n=2,158$} \\
\hline \multirow[t]{3}{*}{ Maternal age at delivery } & $<=18$ & $131(13.7)$ & $123(10.3)$ \\
\hline & $19-34$ & $698(72.8)$ & $976(81.5)$ \\
\hline & $35+$ & $130(13.6)$ & $98(8.2)$ \\
\hline \multicolumn{4}{|c|}{$\chi_{(2)}^{2}=24.942, p<0.001, n=2,156$} \\
\hline \multirow[t]{2}{*}{ Maternal marital status } & Married/living with partner & $324(34.0)$ & $513(43.1)$ \\
\hline & Widowed/separated/divorced/single & $628(66.0)$ & $677(56.9)$ \\
\hline \multicolumn{4}{|c|}{$\chi_{(1)}^{2}=18.299, p<0.001, n=2,142$} \\
\hline \multirow[t]{4}{*}{ Maternal education } & No formal schooling & $9(1.0)$ & $8(0.7)$ \\
\hline & Grade 10 or less & $530(61.1)$ & $597(54.1)$ \\
\hline & Grade $11-12$ & $259(29.8)$ & $375(34.0)$ \\
\hline & Post-school training & $70(8.1)$ & $123(11.2)$ \\
\hline \multicolumn{4}{|c|}{$\chi_{(3)}^{2}=11.972, p<0.01, n=1,971$} \\
\hline \multirow[t]{4}{*}{ Socioeconomic Index } & 3 or less assets & $136(21.5)$ & $225(27.6)$ \\
\hline & $4-5$ assets & $225(35.5)$ & $253(31.0)$ \\
\hline & $6-7$ assets & $168(26.5)$ & $182(22.3)$ \\
\hline & $8-10$ assets & $105(16.6)$ & $155(19.0)$ \\
\hline \multicolumn{4}{|c|}{$\chi_{(3)}^{2}=11.325, p<0.05, n=1,449$} \\
\hline
\end{tabular}


analysed, with the exception of gender. In contrast with children who had not experienced a residential move, children more likely to have changed residence at least once over the period were either White or Asian (3.7\% as compared with $2.3 \%$, and $3.8 \%$ as compared with $2.4 \%$, respectively), born at private hospitals $(13.5 \%$ as compared with $10.2 \%)$ and residing in the inner city or suburbs at birth $(1.0 \%$ as compared with $0.0 \%$, and $6.5 \%$ as compared with $4.1 \%$, respectively). A relatively larger proportion of children who experienced a residential move had biological mother's who were married or living with their partner $(43.1 \%$ as compared with $34.0 \%$ ) and had completed either Grade 11 to 12 schooling (secondary school) or had post-school education (34.0\% as compared with $29.8 \%$, and $11.2 \%$ as compared with $8.1 \%$, respectively). As was the case with the attrition group reported on previously, movement was more frequently associated with participants who were lowest resourced and highest resourced in terms of their socioeconomic categorisations $(27.6 \%$ as compared with $21.5 \%$, and $19.0 \%$ as compared with $16.6 \%$, respectively).

The analysis was extended to contrast children who moved once with children who experienced multiple moves (two or more). Significant differences were found between these two levels of movement and the variables 'maternal education' and 'maternal age at delivery'. A larger proportion of repeated movement amongst children occurred in cases where biological mothers were aged between 19 and 34 years at birth $(84.8 \%$ of repeated movers fell within this category as compared with $79.2 \%$ of single movers). Repeated moves were more frequently associated with children whose biological mothers had Grade 11 to 12 schooling or post-school education $(50.8 \%$ of repeated movers had mothers with these characteristics, as compared with $41.0 \%$ of single movers), while very low levels of repeated moves occurred amongst children whose mothers had no formal education (one out of the eight children in this category had moved more than once).

\section{Exploration of Reasons for Moves}

On the basis of the qualitative responses to the open-ended question concerning predominant reasons for movement, a set of five broad categories were identified that captured the range of responses into which reasons could be coded (see Kok and Collinson 2006; Wentzel et al. 2006). The following categories were identified: reasons concerning employment or finance, those relating to housing requirements, household or partnership formation or dissolution, community-related reasons and reasons around childcare. Reasons provided were not mutually exclusive and multiple codes were assigned to a given reason in cases where the reason spanned more than one of the above categories. Of the 1,930 residential moves undertaken by BT20 children over 14 years, a total of 2,900 reasons codes were generated from the qualitative data. The most common set of reasons for movement, as reported by respondents, were those associated with relationships and family circumstances. These reasons, which accounted for $38.6 \%$ of the total reasons, included (family) household or partnership formation/dissolution, or death of a family member. For example, one caregiver indicated, "I had to move to my husband's family house because I got married." Another caregiver explained that when her husband's grandmother died, she and her child went home to stay with her own mother. 
Reasons associated with accommodation or housing were also frequent $(36.1 \%$ of all reasons). These reasons included moves associated with rental accommodation or housing ownership, or moves relating to specific accommodation requirements or inadequacies. For example, one caregiver explained "We moved to a better place where it was a bigger room than the one in Senaoane." Moves associated with childcare arrangements comprised $14.9 \%$ of all reasons. These included movement associated with the death of the BT20 child's primary caregiver, or moves relating to schooling. A grandmother explained that when the BT20 child's mother passed away, the child moved house to live under her care. Another caregiver indicated that the family had moved because of, "Travelling and school for the children. We found a house in Lenasia and sold the Zakariya Park house. Children could get to school easily." Reasons associated with work or finance such as leaving or entering employment made up $6.3 \%$ of all reasons cited for a child moving. One caregiver indicated that they moved because they could no longer afford the rent in Randburg. Another explained that she found a job as a domestic worker and was offered an outside room with enough space to accommodate her and the BT20 child. Finally, community-related reasons such as movement because of security concerns in an area, or because of the desire to live in a particular neighbourhood comprised $4.1 \%$ of all reasons for residential change. One caregiver explained, "We were too restricted in that neighbourhood because of no safety, so we moved to a safer environment." Another moved because of violence in the hostel in which they were living.

Although the current study does not specifically investigate the movement of children in relation to a biological parent or primary caregiver, the exploration of reasons for movement suggest that the movement of children and primary caregivers do not always correspond to one another. A comparison of the historical address records reflecting primary caregivers' contact details with children's residential addresses recorded in the Residential Move Questionnaire revealed that an average of 7.5\% of caregivers' contact addresses at each time point differed from the residential locations of the BT20 cohort members. The rate of correspondence between primary caregiver's and children's addresses tended to decrease as the children became older, with a $6.2 \%$ discrepancy in addresses at year 1 and an $11.8 \%$ discrepancy at year 14 .

\section{Discussion}

This is the first study that we could identify that investigates child residential mobility in the Greater Johannesburg/Soweto area over time. The findings of the study describe the frequency of residential movements amongst children born in an urban South African context. The majority of children moved at least once during this period, but a third of children never changed residence in their first 14 years. The study also contrasted the movement patterns of cohort members lost to followup with cohort members who continued their participation in BT20. Overall, the largest proportion of moves occurring at each time point took place within the Greater Johannesburg area; however, a large proportion of movement that occurred inter-provincially was associated with study attrition. Residential mobility was found to be associated with high and low household socioeconomic status. That is, better and worse off children were the most mobile. 


\section{Patterns and Frequencies}

By the age of 14, the majority of children in the BT20 cohort had either never moved residence or had moved home only once (74.4\%). On average, $11.1 \%$ of children in the cohort changed residence at any single time point. By comparison, in a study of rural South African children, $21.2 \%$ of the sample were found to have moved within a 2-year period from 2000 to 2002 (Ford and Hosegood 2005). The lower rate of movement amongst the group of children born in Greater Johannesburg suggests stable patterns of residence, with people potentially becoming more permanently anchored to the urban environment. This is further emphasised by the fact that where movement did occur in the current study, the moves primarily took place across suburbs within Greater Johannesburg. This is again in contrast to the rural study where a larger proportion of moves were to destinations outside as opposed to within the study area (Ford and Hosegood 2005).

The study afforded a unique opportunity to investigate the movement patterns of the group of BT20 participants who have remained in the cohort and the group of BT20 participants who were lost to follow-up. This is of particular relevance given the strong correlation between residential movement and study attrition. A set of differing movement trajectories were evident for these two groups of children. For the cumulative attrition cases, the largest proportion of residential movements occurred when the children were aged 4 years or younger, with a substantial proportion of movements to locations outside of the study area. This finding mirrors similar results from the study conducted by Ford and Hosegood (2005), which showed that the youngest children had the highest probability of moving. This suggests that the commencement of schooling may be a stabilising force in children's lives. The relatively high levels of movement observed in the current study at 3-4 years and at 11-12 years seem to coincide with the commencement of school and the juncture of transfers from primary to secondary school.

In contrast to the group of children lost to follow-up, a large proportion of the children who remained in the BT20 study had never experienced a residential move by age 14 . The average residential moves per time point amongst this group of study participants $(9.9 \%)$ was consistent with the results of the HSRC's national survey of public opinion, in which it was found that $10 \%$ of Gauteng-based respondents had changed residence within a 12-month period (Rule 2000). Thus, the study using data from BT20 suggests that urban families and children may be more stable than would be anticipated; however, the length of time since families had settled in the region is likely to be an important factor. A survey of Soweto households conducted in 1997 revealed that many families of migrant origin were currently more permanently established in Soweto, with $41 \%$ of household heads born in the metropolitan area. Of the Soweto Survey respondents, few reported to have moved home frequently (Gilbert and Crankshaw 1999). Future research into the length of time that BT20 families have resided in the area is currently underway.

Within the group of retained cohort members, the propensity to move was found to be highest amongst Whites and lowest amongst Coloureds. Furthermore, mobility within the retained cohort group was associated with the highest and lowest socioeconomic indicators, reflecting movement for both economically advantageous and disadvantageous reasons. These findings coincide with the results of analyses 
conducted by Kok et al. (2003) using South African Census data, in which they found that migration involving a move of a household was associated with higher education levels and income, while migration involving a movement of an individual for reasons of employment (specifically a labour migration) was correlated with lower levels of education and income. A study of rural South African children found that the likelihood of moving was higher amongst children living in households with fewer assets (Ford and Hosegood 2005). The low level of movement observed in this study may be associated with potential poverty of opportunity, with people lacking incentive or resources to facilitate or motivate residential change. As revealed in Gilbert and Crankshaw's Soweto survey (1999), a large proportion of respondents had not improved their housing conditions since their arrival in the area.

\section{Reasons}

The study offered insight into some of the reasons for movement, as well as the potential part of children in decisions around movement. Primary reasons for movement as sited by respondents most frequently centred on changing family and relationship circumstances, or housing requirements. Some parallels may be drawn between these findings and the results of the 2001/2002 HSRC Migration Survey. Although the HSRC survey found that $38 \%$ of total reasons provided for internal migrations were employment related, a significant number of female respondents reported that they had moved because of relationship formation or dissolution (Wentzel et al. 2006). Furthermore, the HSRC survey found that migrations occurring within the urban sector were more commonly driven by personal issues and housing, as opposed to the economic issues that more frequently motivated rural to urban movement streams (Cross 2006).

The results of the current study allude to the fact that children may move independently of primary caregivers for reasons linked to accessing care or schooling. These observations concur with findings from the Agincourt 19992003 study, which revealed that rural-based children moved most frequently in conjunction with the move of a parent, but moves to live with another family member or to access schooling were also common (Kok and Collinson 2006). Similarly, the Western Cape Migration Study found that children entering the Province may take up residence with extended kin, often to access education (Bekker 2002). The discrepancy between primary caregiver's and children's addresses observed in the current study may also be explained by the movement of a primary caregiver from a household where a child remains, such as may occur when caregivers get work in other areas. Thus the relative stability observed within the urban area may suggest that urban children have access to broader care networks, potentially in the form of an extended family, where movements of a parent from a house shared with an extended family does not necessarily imply a movement for a child.

\section{Limitations}

While the study illuminated some of the dynamics around mobility of the group of participants who were lost to follow-up, the extent of their movements are most likely to be under-reported. Further exploration of the patterns of movement amongst this group 
was not possible once contact with the families was lost. Furthermore, the exploration of the relationship between child and caregiver movement patterns warrants more detailed investigation. While it is apparent that movements of urban children in the current sample may occur independently of an existing household or caregiver, an understanding of these movement patterns in relation to families and care networks is important. More in-depth research into reasons for movement will form part of a subsequent study within BT20, with the aim of exploring the differential consequences of movement for children within the context of the factors motivating residential change.

\section{Conclusion}

In conclusion, the results presented in this paper suggest that the frequency of residential movement amongst urban children in Gauteng is not high, particularly during the primary school years. The findings of the study further indicate that mobile children are either socially advantaged or potentially vulnerable. Future research focusing on outcome-oriented data (such as education and health) would assist in informing this picture, both in relation to mobile children, and in the case of those children whose levels of mobility are low. Indeed, research to investigate the impact of mobility on child outcomes is currently underway within the BT20 cohort. Understanding the mobility of children has important policy implications in the areas of education, health and social security provision. Knowledge of the patterns and reasons for residential mobility can support urban planning initiatives and policy concerning service delivery.

Open Access This article is distributed under the terms of the Creative Commons Attribution Noncommercial License which permits any noncommercial use, distribution, and reproduction in any medium, provided the original author(s) and source are credited.

\section{References}

Anderson, A., \& Richter, L. M. (1994). "Birth to Ten": error detection and correction in a longitudinal address database. South African Journal of Epidemiology and Infection, 9, 16-19.

Barbarin, O. A., \& Richter, L. M. (2001). Mandela's children: Growing up in post-apartheid South Africa. New York: Routledge.

Bekker, S. B. (2002). Provincial Government of the Western Cape: migration study in the Western Cape 2001. http://www.capegateway.gov.za/eng/publications/reports_research/M/11369. Accessed 1 October 2008.

Brockerhoff, M. (1995). Child survival in big cities: The disadvantages of migrants. Social Science and Medicine, 40, 1371-1383.

Collinson, M., Kok, P., \& Garenne, M. (2006a). Migration and changing settlement patterns: Multilevel data for policy. Report 03-04-01. Pretoria: Statistics South Africa.

Collinson, M., Lurie, M., Kahn, K., Wolff, B., Johnson, A., \& Tollman, S. (2006b). Health consequences of migration: Evidence from South Africa's rural North-East (Agincourt). In M. Tienda, S. Findley, S. Tollman \& E. Preston-Whyte (Eds.), Africa on the move: African migration and urbanisation in comparative perspective (pp. 308-328). Johannesburg: Wits University Press.

Cross, C. (2006). Migrant motivations and capacities in relation to key migration streams. In P. Kok, D. Gelderblom, J. O. Oucho \& J. van Zyl (Eds.), Migration in South and Southern Africa: Dynamics and determinants (pp. 205-226). Cape Town: HSRC Press. 
Crush, J. (2000). Migrations past: An historical overview of cross-border movement in Southern Africa. In D. A. McDonald (Ed.), On borders: Perspectives on international migration in Southern Africa (pp. 12-24). New York: St. Martin's Press.

Ford, K., \& Hosegood, V. (2005). AIDS mortality and the mobility of children in Kwazulu Natal, South Africa. Demography, 42, 757-768.

Garenne, M. (2003). Migration, urbanisation and child health in Africa: A global perspective. Conference on African migration in comparative perspective, Johannesburg, South Africa, 4-7 June 2003. http:// pum.princeton.edu/pumconference/papers/5-Garenne.pdf. Accessed 1 October 2008.

Gilbert, A., \& Crankshaw, O. (1999). Comparing South African and Latin American experience: Migration and housing mobility in Soweto. Urban Studies, 36, 2375-2400.

Giliomee, H., \& Schlemmer, L. (1985). Up against the fences: Poverty, passes and privilege in South Africa. Cape Town: David Philip.

Hargrove, J. W. (2007). Migration, mines and mores: The HIV epidemic in Southern Africa. Inaugural lecture, Stellenbosch University, November 2007. http://www0.sun.ac.za/sacema/publications/ Hargrove\%20Migration\%20Mines\%20and\%20Mores.pdf. Accessed 1 October 2008.

Hosegood, V., \& Ford, K. (2003). The impact of HIV/AIDS on children's living arrangements and migration in rural South Africa. Conference on African migration in comparative perspective, Johannesburg, South Africa, 4-7 June 2003. http://pum.princeton.edu/pumconference/papers/3Hosegood.pdf. Accessed 1 October 2008.

Jones, S. (1993). Assaulting childhood: Children's experiences of migrancy and hostel life in South Africa. Johannesburg: Witwatersrand University Press.

Kok, P., O’Donovan, M., Bouare, O., \& van Zyl, J. (2003). Post apartheid patterns of internal migration in South Africa. Cape Town: HSRC Press.

Kok, P., \& Collinson, M. (2006). Migration and urbanisation in South Africa. Report 03-04-02. Pretoria: Statistics South Africa.

Magwaza, A. S. (1994). Migration and psychological status in South African black migrant children. Journal of Genetic Psychology, 155, 283.

Murray, C. (1981). Families divided: The impact of migrant labour in Lesotho. Johnnesburg: Ravan.

Norris, S. A., Richter, L. M., \& Fleetwood, S. A. (2007). Panel studies in developing countries: Case analysis of sample attrition over the past 16 years within the Birth to Twenty cohort in Johannesburg, South Africa. Journal of International Development, 19, 1143-1150.

Posel, D. (1991). The making of apartheid 1948-1961 conflict and compromise. Oxford: Clarendon Press.

Posel, D. (2006). Moving on: Patterns of labour migration in post-apartheid South Africa. In M. Tienda, S. Findley, S. Tollman \& E. Preston-Whyte (Eds.), Africa on the move: African migration and urbanisation in comparative perspective (pp. 217-231). Johannesburg: Wits University Press.

Posel, D., \& Casale, D. (2003). What has been happening to internal labour migration in South Africa, 1993-1999? Development Policy Research Unit Working Paper, 03/74. http://www.commerce.uct.ac. za/Research Units/dpru/WorkingPapers/PDF Files/wp74.pdf. Accessed 16 August 2009.

Richter, L. M., Norris, S. A., \& De Wet, T. (2004). Transition from Birth to Ten to Birth to Twenty: The South African cohort reaches 13 years of age. Paediatric and Perinatal Epidemiology, 18, 290-301.

Richter, L. M., Norris, S. A., Swart, T. M., \& Ginsburg, C. (2006). In-migration and living conditions of young adolescents in Greater Johannesburg, South Africa. Social Dynamics, 32, 195-216.

Richter, L. M., Norris, S. A., Pettifor, J., Yach, D., \& Cameron, N. (2007). Cohort profile, Mandela's Children: The 1990 Birth to Twenty study in South Africa. International Journal of Epidemiology, 36, 504-511.

Rule, S. (2000). Geographical preferences and movements. In S. Rule (Ed.), Democracy South Africa: Public opinion on national priority issues (pp. 66-69). Pretoria: HSRC Press.

South African Cities Network. (2006). State of the cities report 2006. Johannesburg: South African Cities Network.

Statistics South Africa. (2006). Provincial profile 2004: Gauteng. Report 00-91-07. Pretoria: Statistics South Africa.

Statistics South Africa. (2007). Mid-year population estimates, South Africa: 2007. Statistical Release P0302. Pretoria: Statistics South Africa.

Tucker, C. J., Marx, J., \& Long, L. (1998). "Moving on": Residential mobility and children's school lives. Sociology of Education, 71, 111-129.

Van der Waal, C. S. (1996). Rural children and residential instability in the Northern Province of South Africa. Social Dynamics, 22, 31-54. 
Wentzel, M., \& Tlabela, K. (2006). Historical background to South African migration. In P. Kok, D. Gelderblom, J. O. Oucho \& J. van Zyl (Eds.), Migration in South and Southern Africa: Dynamics and determinants (pp. 71-96). Cape Town: HSRC Press.

Wentzel, M., Viljoen, J., \& Kok, P. (2006). Contemporary South African migration patterns and intentions. In P. Kok, D. Gelderblom, J. O. Oucho \& J. van Zyl (Eds.), Migration in South and Southern Africa: Dynamics and determinants (pp. 171-204). Cape Town: HSRC Press.

Wilson, F. (1972). Labour in the South African gold mines 1911-1969. Cambridge: Cambridge University Press.

Carren Ginsburg (MSc) is a Researcher and $\mathrm{PhD}$ student within the Birth to Twenty Research Programme, University of the Witwatersrand, Johannesburg. Her research interests are in the area of child well-being, migration and urbanisation.

Shane Norris $(\mathrm{PhD})$ is a Welcome Trust Research Fellow within the Birth to Twenty Research Programme and MRC Mineral Metabolism Research Unit, Department of Paediatrics, University of the Witwatersrand. He also holds an honorary appointment at the University of Cambridge. His research interests are in the area of child and adolescent development and metabolic disease risk.

Linda Richter $(\mathrm{PhD})$ is the Executive Director of the Child Youth Family and Social Development programme at the Human Sciences Research Council in South Africa. She also holds honorary appointments at the University of KwaZulu-Natal, the Witwatersrand and Oxford. Her research interests are in the area of child and adolescent poverty and disadvantage, and interventions to address them.

David Coplan $(\mathrm{PhD})$ is a Lecturer in the Department of Social Anthropology, University of the Witwatersrand Johannesburg. His research interests include urban anthropology, social organisation and border studies. 